\title{
Traveling Wave Based Security Plan for Bipolar Transmission Boundary
}

\author{
C. Poongothai, K. Gayathri
}

\begin{abstract}
The High Voltage Direct Current (HVDC) transmission framework is progressively utilized and quickly creating in the parts of long separation and huge limit control transmission. An epic voyaging wave-based security plot for bipolar HVDC boundary is furnished in this paper. The insurance dependent on voyaging wave utilized as the primary assurance for HVDC transmission boundary. MATLAB model is used to extract the results from various conditions.
\end{abstract}

Keywords : HVDC, Flawed boundary determination, voyaging wave, HVDC framework, Rectifier, Inverter.

\section{INTRODUCTION}

High-Voltage Direct Current transmission framework had been progressively utilized as a result of the focal points in long separation and huge limit transmission. Nonetheless, the current voyaging wave-based insurance for HVDC transmission boundary isn't touchy enough for appropriately recognizing the inward issue with high deficiency opposition [1]. A HVDC electric control transmission structure moreover is known as a power super turnpike or an electrical super roadway uses direct stream for the mass transmission of electrical control on the other hand with the more normal trading stream (cooling) systems.Fig.1.shows HVDC boundary boundary. For long-partition transmission, HVDC systems may be increasingly reasonable and suffer lower electrical hardships.

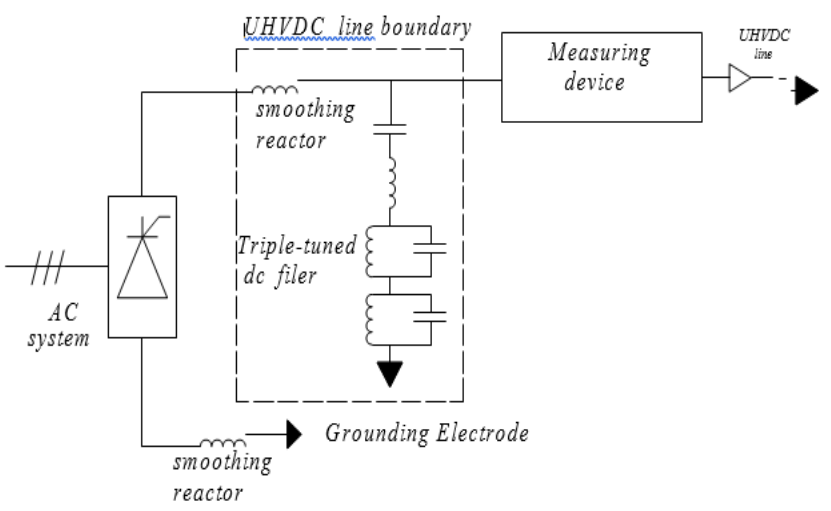

Fig.1. UHVDC boundary

HVDC permits zero power transmission between nonsynchronous AC transmission frameworks. Since the facility course through a HVDC affiliation will be controlled freely of the stage edge among supply and burden, it will settle a system against unsettling influences owing to fast

Revised Manuscript Received on October 25, 2019.

* Correspondence Author

C. POONGOTHAI* Ph.D scholar, Dept of Electrical Engineering Annamalai University, Annamalai Nagar, India,gothaimekala93@gmail.com.

K. GAYATHRI, Associate Professor, Dept of Electrical Engineering Annamalai University, Annamalai Nagar, India, g.gayathri3@gmail.com. changes up to speed. HVDC likewise permits move of intensity between framework running at numerous frequencies, as an example, fifty $\mathrm{Hz}$ and sixty $\mathrm{Hz}$. This improves the soundness and economy of each framework, by allowing trade of intensity between inconsistent systems. For safe activity of HVDC frameworks, the identification and quick leeway of issues in the HVDC boundary are significant [14]. The Ongoing examination chip away at primary securities boundary can be essentially classified into 2 sorts. 1) Limit assurance. The boundary limit, comprising of the DC channel and smoothing out, has a lessening impact at trademark music and huge recurrence parts. The rule of limit assurance depends on the way that trademark sounds and high recurrence segments can scarcely arrive at the estimating point if an outside issue happens. Reference [11] and [12] contemplated consonant current positioned limit securities by methods for Fourier change. This furnished a high-recurrence voltage segment-based limit security, which utilizes wavelet transform algorithm. 2) unique rule of voyaging wave-based assurance. HVDC presents an assurance plan dependent on 0 mode and positive-mode voyaging waves[13].

\section{II.TRAVELLING WAVE PROTECTION}

Voyaging wave-based techniques are not worthwhile for HVDC boundary assurance than for AC boundary insurance. In the AC boundary, the deficiency particle can't create a moving voyaging wave for the issue origin edge at 0 intersection although the DC boundary doesn't obtain this issue. Voyaging wave-based strategies still have issues that point of confinement their application, for example, lacking numerical instruments to speak to voyaging wave and not being equipped for identifying close-up deficiencies [13].Traveling waves coming about because of the flaw can likewise give data to blame characterization and blamed stage determination in $\mathrm{AC}$ power frameworks [14]. The portion of HVDC transmission boundary is commonly extremely long and presented to the confused and insidious situations, which compose the development of twofold fault no more uncommon.

HVDC transmission boundary security has not been applied in pragmatic HVDC venture, so this paper will in any case do contemplate on the current HVDC transmission boundary insurance in reasonable HVDC venture. So as to offer theoretic help for practical activity of HVDC transmission framework, this paper for the most part researches on the capacity of standard, the setting rule of threshold, the influencing factors on security and the presentation of DC boundary assurance, which incorporates. 


\section{A. The Demonstrating of HVDC transmission frame work}

The qualities and parameters of every component like converter and its control framework in HVDC framework are presented, at that point HVDC transmission framework are displayed MATLAB, and by the simulation, the model is confirmed both in enduring state and transient state.

\section{B. The Working quality of DC boundary protection}

The standard, calculation and setting rule of limit are presented and broke down right off the bat. At that point by reproduction, the effect instrument of influencing components like sampling frequency, boundary elements, fault distance and fault impedance on DC boundary is looked into.

\section{The exhibition of DC boundary protection}

As indicated by the setting rule of edges, the edge is picked up by recreation and figuring. At that point by recreation and computation, the working trademark like affectability and speed of every DC boundary insurance are broke down and finished up. In the meantime, by setting different DC boundary issue and issue outside the insurance zone, the entire DC boundary security execution is investigated and closed.

\section{Improved voyaging wave security}

So as to improve the sensitivity of voyaging wave security, the voyaging wave is substituted by the differential mode wave to shape the rule for guaranteeing the choice solicitation.

\section{BIPOLAR TRANSMISSION BOUNDARY}

In bipolar transmission a handful of conductors is employed, every at a high potential relating to ground, in inverse extremity. Since these conductors should be protected for the complete voltage, transmission boundary price is more than a monopole with associate arrival conductor. Be that because it could, there square measure numerous advantage points to bipolar transmission which might build it associate enticing selection. Therefore on keep harmonious flows from getting into the DC boundary, swish reactors and channels were introduced at the DC surface. This unit carries on sort of a limit, interference high-request repetition flows. A bipolar association has a pair of conductors, one positive and also the different negative on earth. the main target of converters at each terminal station square measure earthed by suggests that of anode boundary. The voltage at intervals is corresponding to multiple times the voltages fitfully each of the two conductors and ground.

\section{A. 12 Pulse Converter}

A typical converter station with two 12 heartbeat converter bunch for each pole is appeared in figure underneath. The square design of converter station is given beforehand. This as a general rule involves two three phase converter platforms related in course of action to outline a 12 pulse converter unit as showed up in underneath chart. The hard and fast number of valves in such a unit is twelve. The valves can be packaged as single valve, twofold valve or quadrivalve courses of action. Each valve is used to switch in area of a climate control system voltage waveform. The converter is energized by converter transformers related in star/star and star/delta strategies. The valves are cooled by means of air, oil, water of freon. Liquid cooling using deionized water is continuously beneficial at that point realizes the abatement of station disasters. The structure of valves relies upon the deliberate thought where each module contains a set number of game plans related thyristor levels.

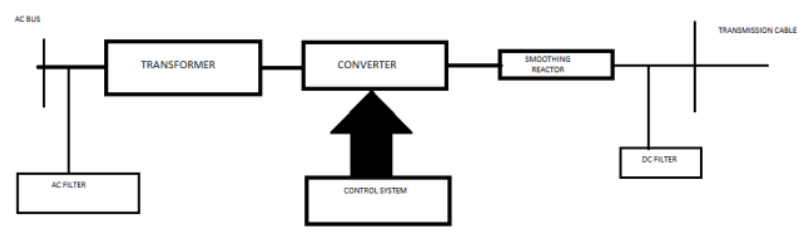

Fig.2.One-boundary diagram of converter station

Valve ending sign are created within the convertor management at ground potential and are transmitted to every thyristor within the valve through a fiber optic lightweight guide structure. The valves are bonded exploitation snubber circuits, cautious ending and gapless reenactment arrestors. Fig.2. shows the One-limit define of convertor station.

\section{PROPOSED PROTECTION SCHEME}

HVDC transmission framework can be characterized into two sorts as per the quantity of terminals: single-shaft HVDC transmission framework and twofold post HVDC transmission framework. In this paper, the exploration depends at once shaft HVDC framework, which can be isolated into three sections: AC force sources, converter stations and DC transmission boundary. At the point when the power streams from converter 1 to converter 2 , converter 1 is the rectifier and converter 2 is the inverter; despite what might be expected, converter 1 is the inverter and converter2 is the rectifier. The converter station more often than not finishes up converter, AC channel, transformer, reactor and DC channel.

\section{A.Identification principle of fault section}

$\mathrm{BR}$ and BI are boundary limits of the rectifier and inverter side. As indicated by the voyaging wave hypothesis, the shortcoming produced forward voyaging wave, $\mathrm{u}_{\mathrm{f}}$, and in reverse voyaging wave, $u_{b}$, will multiply from the issue minute that a blemish occurs. $\mathrm{u}_{\mathrm{f}}$ and $\mathrm{u}_{\mathrm{h}}$ can be taken as

$$
\begin{gathered}
u_{f}=\left(\Delta u+z_{c} \Delta i\right) / 2 \\
u_{b}=\left(\Delta u-z_{c} \Delta i\right) / 2 \\
\Delta u=u_{\text {fault }}-u_{\text {normal }} \\
\Delta i=i_{\text {fault }}-i_{\text {normal }}
\end{gathered}
$$

where $\mathrm{zc}$ is that the surge electric resistance. $\mathrm{u}$ and that i square measure disadvantage elements of the voltage and current. $u_{\text {fanlt }}, i_{\text {fanlt }}$ square measure the deliberate voltage and current once the flaw happening, and $\mathrm{u}_{\mathrm{nnrmal}}$, $\mathrm{I}_{\text {normal }}$ square measure the deliberate voltage and current of the everyday activity. The hour of gathering deficiency elements is chosen by the start unit.

Fig.3. shows the crosswise boundary of voyaging wave spreading method for the disadvantage happening at the rectifier aspect. As is appeared within the figure, simply the forward voyaging wave, $\mathrm{u}_{\mathrm{f}}$, are often recognized 
by the estimating convenience within the time interim [t0, $\mathrm{t} 0+2 \mathrm{l} / \mathrm{vl}$. consequently, the distinguished in reverse voyaging wave are often communicated as

$$
u_{b}=0
$$

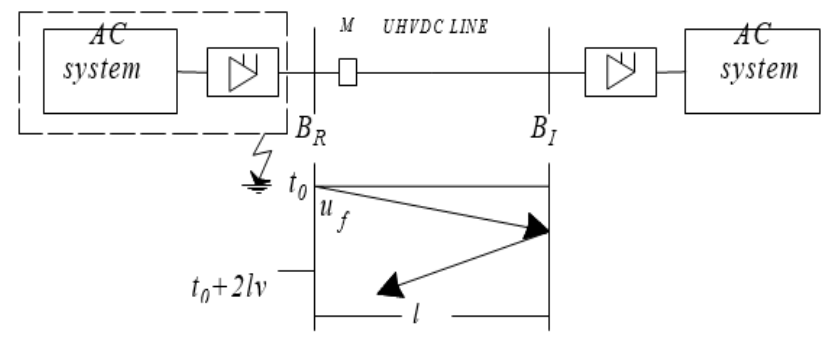

Fig.3. Voyaging wave spreading process for the fault at the rectifier side

As is showed up in Fig.4, when an inadequacy occurs at the inverter side, the basic wave recognized by the evaluating device is the retrogressive traveling wave, ub1, spreading from the inverter side. Inside the time between time [ $\mathrm{t} 0$, $\mathrm{t} 0+2 \mathrm{l} / \mathrm{v}]$, the perceived backward journeying wave can be conveyed as

$u_{b}=u_{b l}$

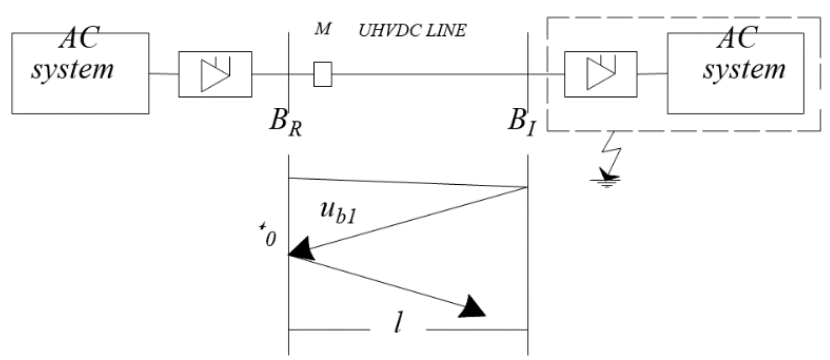

Fig.4. Voyaging wave spreading process for the fault at the inverter side

In addition, the underlying in reverse making a trip wave needs to go through the boundary limit when a shortcoming at the inverter side happens. Along these-boundary, the distinguished in reverse voyaging wave ought to be smooth and doesn't have a fiasco point

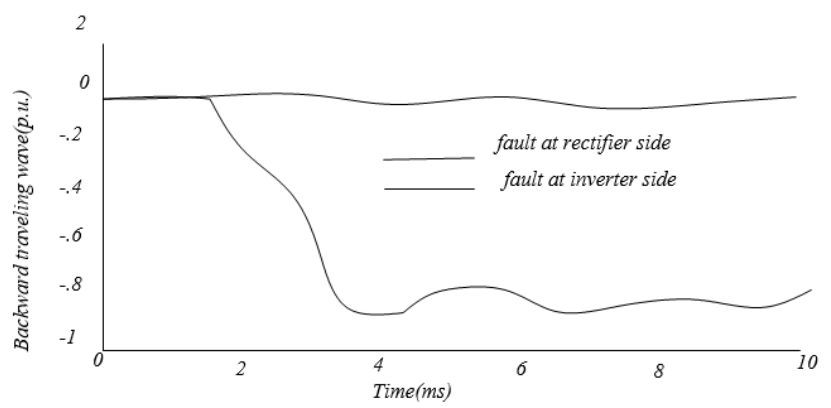

Fig. 5 The retrogressive voyaging surges of shortcomings at the rectifier and inverter side

Fig.5 shows the retrogressive voyaging surges of shortcomings at the rectifier and inverter side (The underlying voyaging wave is recognized at $1 \mathrm{~ms}$ ). It very well may be seen that the retrogressive voyaging wave of the flaw at inverter side changes easily, and the regressive voyaging wave of the shortcoming at rectifier side keeps up around the $0^{\text {th }}$ worth.

Fig. 6 shows the grid graph of the voyaging wave proliferating process for the inward flaw. The underlying wave is the retrogressive voyaging wave ub1, spreading from the shortcoming point. $u_{b} \square u_{b 1}+u_{b 2}+u_{b 3}+$

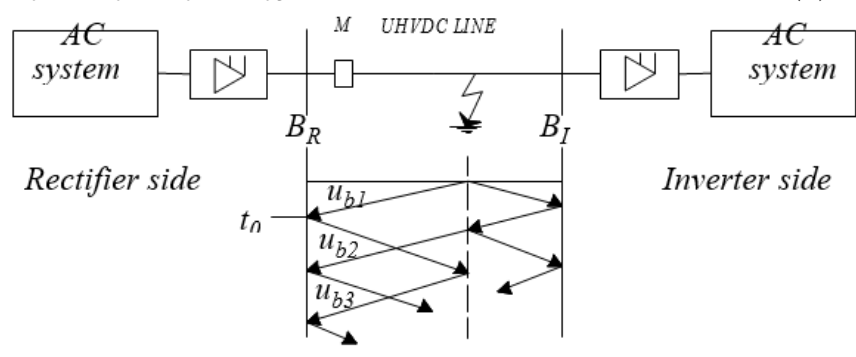

Fig.6. Voyaging wave AC Process for the Internal Fault

The going with in turn around traveling waves can be requested into two sorts: 1) ub2, multiplying from the inverter side in the wake of being reflected by the cutoff, BI, and refracted by the blemish point; 2) ub3, which spreads in the wake of being reflected by the inadequacy point. Inside the time interval $[\mathrm{t} 0, \mathrm{t} 0+2 \mathrm{l} / \mathrm{v}]$, the going with condition imparts the recognized backward traveling wave.

\section{SIMULATION RESULTS}

A HVDC electric control transmission structure moreover called a power super turnpike or an electrical super roadway uses direct stream for the mass transmission of electrical control on the other hand with the more normal trading stream (cooling) systems.

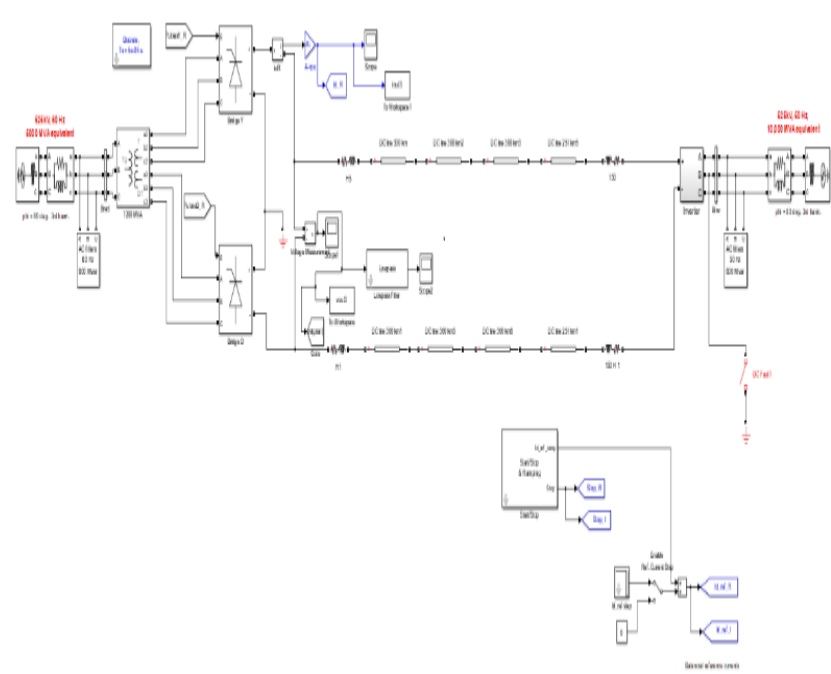

Fig.7.Simulink Block Diagram

A \pm 800 potential unit UHVDC system is modeled in MATLAB/EMTDC.Different with the \pm 500 potential unit HVDC structure, the HVDC structure is formed out of 2 12-pulse remuneration associates in course of action per shaft. The boundary model depends upon the repeat ward stage model. The management model rectifier facet comprehends the parts of tolerating current management and least ending purpose constrainment management. The model of electrical converter facet comprehends the parts of inevitable current-control,extinction edge management and current inclination management. Moreover, the voltage subordinate current most extreme management is applied at the various sides. The reenactment time step is ten US and therefore the testing rate is ten kilocycle per second. 


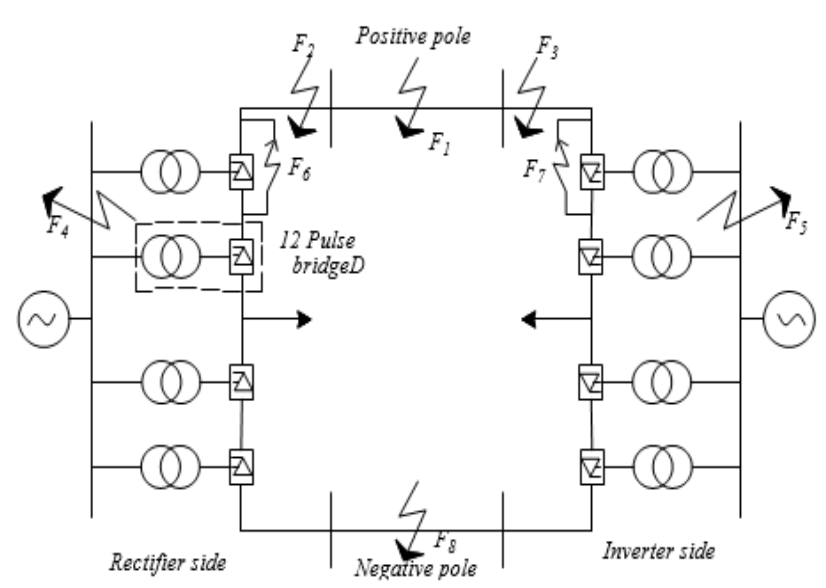

Fig.8.Block diagram of $\pm 800 \mathrm{kV}$ UHVDC system

Moreover, the voltage subordinate current most extreme control is applied at the different sides. The reenactment time step is 10 us and the testing rate is 10 $\mathrm{kHz}$.

\begin{tabular}{|c|c|c|}
\hline Variable & Rectifier side & Inverter side \\
\hline $\begin{array}{c}\mathrm{U}_{\text {ac }} \text { (supply voltage, } \\
\text { boundary to } \\
\text { boundary) } / \mathrm{kV}\end{array}$ & 525 & 525 \\
\hline $\begin{array}{c}\text { Equivalent } \\
\text { impedance/ohm }\end{array}$ & $8.66 \square 83.86$ & $5.51 \square 86.91$ \\
\hline DC filter & $\begin{array}{c}\text { Triple tuned } \\
12 / 24 / 36\end{array}$ & $\begin{array}{c}\text { Triple tuned } \\
12 / 24 / 36\end{array}$ \\
\hline $\begin{array}{c}\mathrm{L}_{\mathrm{p}} \text { (smoothing } \\
\text { reactor on pole } \\
\text { bus }) / \mathrm{mH} \\
\end{array}$ & 150 & 150 \\
\hline $\begin{array}{c}\mathrm{L}_{\mathrm{n}} \text { (smoothing } \\
\text { reactor on neutral } \\
\text { bus }) / \mathrm{mH}\end{array}$ & 150 & 150 \\
\hline $\begin{array}{c}\text { Transmission } \\
\text { boundary length } / \mathrm{km}\end{array}$ & \multicolumn{2}{|c|}{1451} \\
\hline $\begin{array}{l}\text { Transmission } \\
\text { capacity/MW }\end{array}$ & \multicolumn{2}{|c|}{5000} \\
\hline
\end{tabular}

Table 1. Parameters of Triple-Tuned DC Filter

\section{RESULT AND DISCUSSIONS}

The protection of positive boundary is chosen as a result of the verification target of simulation tests. With the aim to see the identification performance of the fault section and faulty boundary, differing types of fault area unit simulated as shown in Fig below.

\section{A. Fault in Normal Operating Condition:}

Under ordinary working conditions, control framework gear or limit convey typical voltages and flows which brings about a more secure activity of the framework. In any case, when deficiency happens, it makes too much high flows stream which makes the harm hardware's and gadgets.

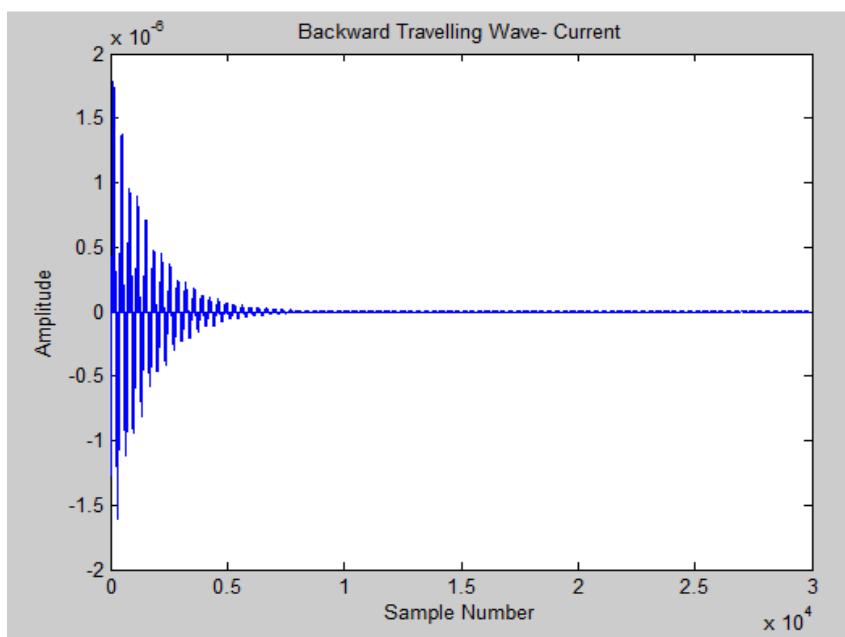

Fig.9.Backward Travelling Wave-Current at Normal Operating Condition

Fig.9. Shows Backward Travelling Wave-Current at Normal Operating Condition. Were $\mathrm{X}$ axis representing sample number and $\mathrm{Y}$ axis represents amplitude.

Fig.10.Backward Travelling Wave-Voltage at Normal Operating Condition

Fig.10. Shows Backward Travelling Wave-Voltage at Normal Operating Condition. Were $\mathrm{X}$ axis representing sample number and $\mathrm{Y}$ axis represents amplitude.

\section{B. Fault in Rectifier Side}

In HVDC framework, blames on rectifier-side or inverter side effectsly affect framework strength. The different kinds of shortcomings are considered in the HVDC framework which causes because of glitches of valves and controllers, failure to discharge and short out over the inverter station, flashover and three stage cut off.

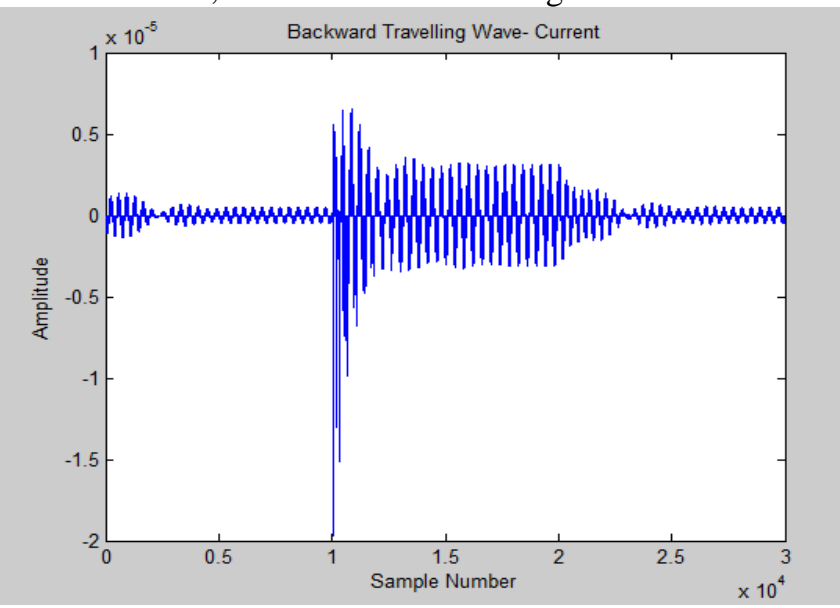

Fig.11.Backward Travelling Wave-Current at Rectifier Side

Fig.11. Shows Backward Travelling Wave-Current at Rectifier Side. Were $\mathrm{X}$ axis representing sample number and $\mathrm{Y}$ axis represents amplitude. 


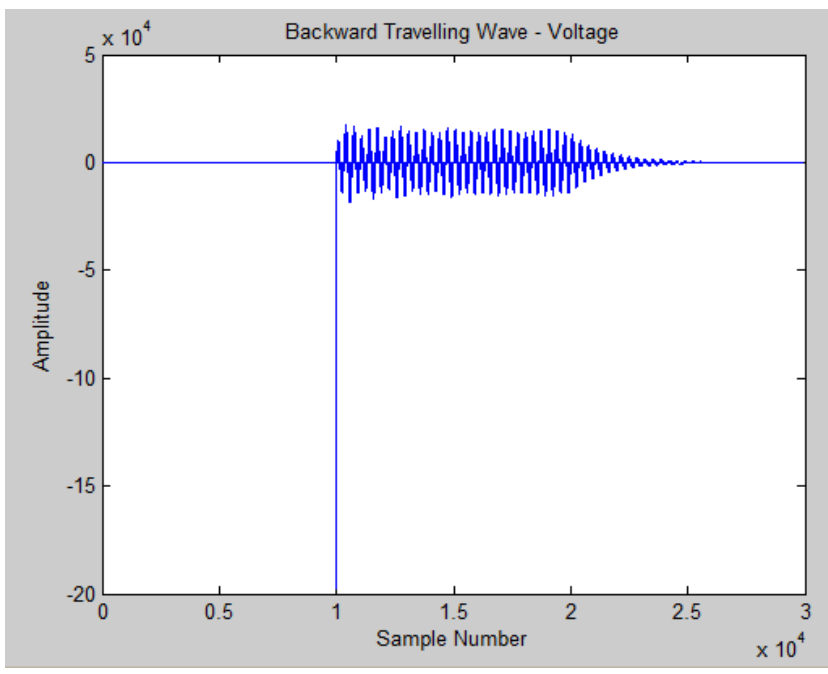

Fig.12.Backward Travelling Wave-Voltage at Rectifier Side

Fig.12.Shows Backward Travelling Wave-Voltage at Rectifier Side. Were $\mathrm{X}$ axis representing sample number and $\mathrm{Y}$ axis represents amplitude.

\section{C.Fault in Inverter Side}

Inverters are generally dependable and should keep going for a long time. Nonetheless, any electronic gadget can glitch and inverters do contain parts, for example, electrolytic capacitors, varistors and transfers that all wear out with age.

The most widely recognized flaw we manage is the place the inverter has turned out badly. Now and again amazing, different occasions they report an issue. This can now and then be a real inverter flaw, for example, a bombed transfer, or it very well may be that the inverter has identified something incorrectly and has closed down for security reasons.

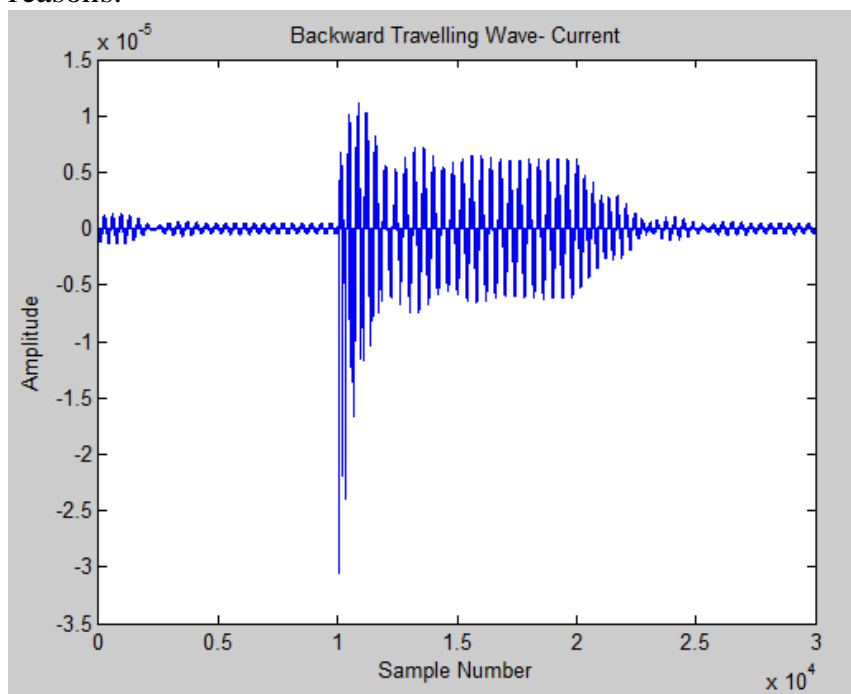

Fig.13.Backward Travelling Wave-Current at Inverter Side

Fig.13.Shows Backward Travelling Wave-Current at Inverter Side. Were $\mathrm{X}$ axis representing sample number and $\mathrm{Y}$ axis represents amplitude.

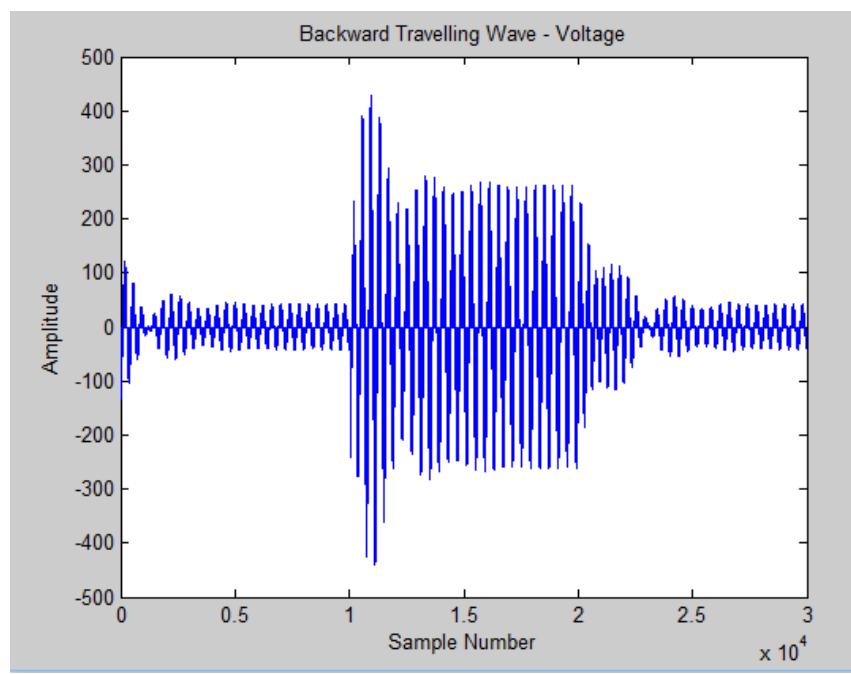

Fig.14.Backward Travelling Wave-Voltage at Inverter Side

Fig.14.Shows Backward Travelling Wave-Voltage at Inverter Side. Were $\mathrm{X}$ axis representing sample number and $\mathrm{Y}$ axis represents amplitude in the event that the inverter is out of guarantee, we will cite for a decent quality supplanting with a multiyear guarantee. There are additionally redesign choices accessible for a top-notch framework with a multiyear guarantee that will outlive your Feed in Tariff. Inverter deficiencies require two fix visits, one to analyze the flaw and afterward one to fix or supplant the inverter.

In this chapter all the results from normal operating conditions, rectifier side, inverter side in HVDC systems are extracted and transients are recorded.

\section{CONCLUSIONS}

An epic voyaging wave primarily based principle assurance conspire for HVDC bipolar transmission boundary is projected during this paper, whose primary units are deficiency order that's traditional operational condition, Rectifier aspect, electrical converter aspect. the excellence of the retrograde voyaging wave between the inward defect and outdoors deficiency is used to differentiate the problem space. The extremity traditional for the voltage flaw half is used to differentiate the defective boundary. the safety set up is performed within the time space, and simply must use the one shaft voltage and current data of the rectifier aspect. Recreation and field data tests detect that the projected assurance set up will accurately distinguish the flaw section and defective boundary within the \pm 800 potential unit UHVDC framework and \pm 500 potential unit HVDC framework. Therefore, the faults in various conditions are detected using MATLAB and results were extracted.

\section{REFERENCES}

[1] H. Rao, B, Luo, X.L. Li, Z.Y. Cai and L.C. Li, "Development of $\pm 800 \mathrm{kV}$ UHVDC transmission technology in China", in Int. Conf. on High Voltage Eng. and App., 2008, pp. 1-7.

[2] H.C. Shu, X.C. Tian, J. Dong, G.B. Zhang, K.Z. Liu, S.Y. Sun and Y. Yang, "Simulation and analyses for Yun-Guang $\pm 800 \mathrm{kV}$ HVDC transmission boundary protection system", Proc. of the CSEE, vol. 31, no. 31, pp. 179-188, 2011.

[3] A.M. Li, Z.X. Cai, Q.Z. Sun, X.H. Li, D.Y. Ren, and Z.M. Yang, "Study on the dynamic performance characteristics of HVDC control and protections for the HVDC boundary 
fault", in Proc. Power Energy Soc. Gen. Meeting, 2009, pp. 1-5.

[4] J. L. Suonan, J.K. Zhang, Z.B. Jiao, L.M. Yang and G.B. Song, "Distance protection for HVDC transmission boundarys considering frequency-dependent parameters", IEEE Trans. Power Del., vol. 28, no. 2, pp. 723-732, 2013.

[5] M. Xu, Z. X. Cai, K. L. Han and Y. J. Zhang, "A sensitive and high-speed traveling wave protection scheme for HVDC transmission boundary", Int. Trans. Electr. Energ. Syst., vol. 23, no. 8, pp. 1304-1316, 2013.

[6] Z.Y. Liu, Y.B. Shu, W.L.Zhang and Y.Z. Zhang, "Study on voltage class series for HVDC transmission system", Proc. of the CSEE, vol. 28, no. 10 , pp. $1-8,2008$

[7] X.X. Cheng, J.Z. Lv, R.F. Gou and J. Zhao, "Study for arrangement of the smoothing reactor in $\pm 800 \mathrm{kV}$ UHVDC Project", in Int. Conf. on High Voltage Eng. and App., 2008, pp. 371-374.

[8] H. Zhou, X.L. Chen, R.H. Chen, D.J. Wang, S.C. Yuan and K. Sun, "Analysis on insulation coordination scheme for $\pm 800 \mathrm{kV}$ DC converter station", Power System Tech., vol. 35, no. 11, pp. 18-24, 2011.

[9] Y. Pu, C. Shu, W.Y. Jiang, Y. Shi, J.F. Hao, Y. Tao, W.M. Ma and .W.Y.

[10]Yin, "Real-time simulation test for secondary system of $\pm 660 \mathrm{kV}$ HVDC power transmission demonstration project from Ningdong to Shandong and countermeasures to key problems", Power System Tech., vol. 35, no. 1, pp. $76-83$

[11] X.D. Zheng, N.L. Tai, J.S. Thorp and G.L. Yang, "A transient harmonic current protection scheme for HVDC transmission boundary," IEEE Trans. Power Del., vol.27, no.4, pp. 2278-2285, Oct. 2012.

[12]G.B. Song, X. Chu, S.P. Gao, X.N. Kang and Z.B. Jiao, "A new whole-boundary quick-action protection principle for HVDC transmission boundarys using one-end current", IEEE Trans. Power Del., vol. 30, no. 2 , pp. 599-607, 2015.

[13]X.L. Liu, A. H. Osman and O. P. Malik, "Hybrid traveling wave/ boundary protection for monopolar HVDC boundary", IEEE Trans. Power Del., vol. 24, no. 2, pp. 569-578, 2009.

[14]Y. Zhang, N.L. Tai and B. Xu, "Fault analysis and traveling-wave protection scheme for bipolar HVDC boundarys", IEEE Trans. Power Del., vol. 27, No.3, pp. 1583-1591, 2012.

[15]H.C. Shu, K.Z Liu, S.Q. Zhu, G.B. Zhang, Z.Z. Zhu and M. Zhang, “ $\pm 800 \mathrm{kV}$ UHVDC transmission boundary protection based on single end electrical transient protection", Proc. of CSEE, vol. 30, no. 31, pp. 108$117,2010$.

[16]H.C Shu, X.C Tian and Y.T Dai, "The identification of internal and external faults for $\pm 800 \mathrm{kV}$ UHVDC transmission boundary based on S-transform of the polarity wave", in Int. Conf. on Image and Signal Processing, 2010, pp. 3060-3063.

[17]F. Kong, Z.G. Hao, S. Zhang and B.H. Zhang, "Development of A Novel Protection Device for Bipolar HVDC Transmission Boundarys", IEEE Trans. Power Del., vol. 29, No.5, pp. 2270-2278, 2014.

[18]N.G. Hingorani, "Transient overvoltage on a bipolar HVDC overhead boundary caused by DC boundary faults", IEEE Trans. Power App. and Sys., vol. 89, No.4, pp. 592-602, 1970 .

\section{AUTHORS PROFILE}

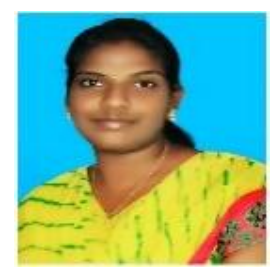

C. Poongothai was born on August 17, 1993. She completed her B.E. degree in Electrical and Electronics in 2014.She completed her M.E Power Systems in Annamalai University, India. Currently pursuing $\mathrm{Ph} . \mathrm{D}$ in Electrical Engineering Annamalai University. Her research interests include power system protection, fault diagnosis and artificial intelligence techniques to power systems.

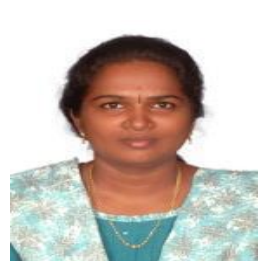

K.Gayathri was born on April 10,1976.She completed her B.E. degree in Electrical an Electronics in 1999, M.E. degree in Power Systems in 2005 and also awarded her Ph.D in Electrical Engineering in September 2010 at Annamalai University. She is presently working as an Assosiate Professor at Annamalai University, India. She has 34 publications to her credit. Her research interests include power system operation and control, power system analysis, fault diagnosis, artificial intelligence techniques, restructuring and restoration to power systems. 